\title{
Acute nutritional ketosis: implications for exercise performance and metabolism
}

Pete $J \operatorname{Cox}^{1,2^{*}}$ and Kieran Clarke ${ }^{1}$

\begin{abstract}
Ketone bodies acetoacetate (AcAc) and D- $\beta$-hydroxybutyrate ( $\beta H B$ ) may provide an alternative carbon source to fuel exercise when delivered acutely in nutritional form. The metabolic actions of ketone bodies are based on sound evolutionary principles to prolong survival during caloric deprivation. By harnessing the potential of these metabolic actions during exercise, athletic performance could be influenced, providing a useful model for the application of ketosis in therapeutic conditions. This article examines the energetic implications of ketone body utilisation with particular reference to exercise metabolism and substrate energetics.
\end{abstract}

Keywords: Ketone body, Ketosis, Ketone ester, Exercise performance, Nutrition

\section{Review}

Dietary intake influences metabolism

An ancient Spanish proverb 'Diet cures more than the lancet' suggests that the importance of diet in maintaining good health is an age-old concept. Mechanisms by which the body uses the fuels we eat to sustain life, or in the case of excess, store the surplus energy, have fascinated generations of scientists. Carbohydrates, fat, protein and, for some, alcohol are the fundamental sources of dietary energy. Whilst the numbers of dietary macronutrients (food groups) are limited, the particular composition and relative contribution of these dietary groups to our calorific needs vary widely. Until recently, little was known of the metabolic systems that linked diet with human function. In 1937, Krebs made arguably the most important breakthrough in biochemistry [1], describing a cycle of enzymatic reactions uniting dietary fuel combustion with cellular energy provision. This final common pathway for substrate metabolism has allowed the detailed study of the flow of energy transformation (energetics) from dietary sources to the 'energy currency' adenosine triphosphate (ATP).

\section{Exercise the litmus of metabolic performance}

Over the last century, our understanding of the fundamental processes underlying human performance has expanded

\footnotetext{
* Correspondence: petejcox456@gmail.com

'Department of Physiology, Anatomy and Genetics, University of Oxford,

Sherrington Building, Parks Road, Oxford OX1 3PT, UK

${ }^{2}$ Department of Cardiovascular Medicine, University of Oxford, Oxford, UK
}

greatly. At the intersection of elite sport and substrate, metabolism lays the potential to investigate the processes that define the limits of human physiology.

The onset of acute exercise triggers a rapid increase in demand for substrate and oxygen (mediated via an increase in cardiac output), with metabolic rate raised up to 100-fold above resting conditions during high-intensity exercise [2]. Depending on the relative intensity of exercise, durations of physical effort may last for minutes, hours or even days, placing large metabolic, structural and cognitive demands on body systems to sustain this output. Similar changes occur in many clinical disease states with high energy requirements, elevated cardiac output and limited tissue oxygen supply, characteristic of high dependency care, surgery or medical emergencies. The functional demands of exercise can be used to quantify responses to treatment [3], or as a diagnostic tool to identify factors limiting physical capacity [3,4]. Exercise therefore provides an ideal tool for the examination of human physical capacity and its controlling factors, under reproducible conditions.

\section{High-performance athletes as models of fuel metabolism}

In many respects, some of the most refined examples of human physiology and metabolism are to be found in the highly trained, athletic cohorts of competitive sport. In particular, endurance sports involving great muscular recruitment and high levels of aerobic fitness induce mitochondrial [5,6] and muscular adaptations [7-9] making such athletes ideal to study fuel metabolism. Aerobic 
endurance training increases mitochondrial oxidative capacity and increases selection of fatty acids for fuel at a given exercise intensity [10-12]. Increased expression of proteins involved in plasma membrane transport [13-16], and $\beta$-oxidation of fats are also well described in athletic cohorts [17]. Similarly, increases in the capacity of skeletal muscle to oxidise other blood-borne substrates such as ketone bodies have been demonstrated following athletic training $[18,19]$. Athletes therefore represent a useful model to further examine fuel metabolism, with predictable responses to exercise stress [12], and a well-characterised metabolic phenotype [20].

\section{Ketone body production: the evolutionary response to energy crisis}

Ketone bodies are fuels endogenously produced by the body from mobilised fat in response to a variety of physiological [21] or pathological conditions [22]. Ketone bodies, acetoacetate (AcAc) and D- $\beta$-hydroxybutyrate $(\beta \mathrm{HB})$, are respiratory fuels that can be oxidised by most body tissues [21] and are formed in large quantities (up to $150 \mathrm{~g} /$ day) by the liver in response to low blood glucose and insulin $[23,24]$.

Ketogenesis is an evolutionary adaptation conserved within all higher order organisms to sustain survival during famine, illness or energetic stress [25]. In particular, the capacity to survive for long periods on endogenous fuel reserves is a trait of particular importance to humans where our relatively large brain size renders a steady supply of glucose critical for cerebral function. In a series of experiments in the 1960s, Cahill demonstrated the importance of cerebral ketone body oxidation in starvation, where up to $60 \%$ of the brain energy needs are derived from ketones, replacing glucose as its primary fuel [26-28]. In turn, the ketone-compensated reduction in glucose utilisation rate, and preservation of gluconeogenic protein stores [29], enables a profound increase in the capacity for survival [27]. The evolutionary effect of ketone bodies is therefore to spare carbohydrate reserves, and muscle protein, whilst themselves being an alternative energy source.

\section{Exercise parallels starvation metabolism}

Clearly, the protracted demands of starvation physiology occur on a much accelerated scale during sustained endurance exercise. Both conditions place a premium on glucose supply, with the finite concentrations of muscular glycogen known to be a strong determinant of exercise tolerance [30,31]. Therefore, ketosis as an evolutionary adaptation to conserve carbohydrates may provide an alternative energy substrate to power working muscle, in turn sparing intramuscular fuels. However, the application of ketone body metabolism in this context has not been appreciated.
Historically, nutritional strategies to acutely influence fuel selection during heavy aerobic exercise have largely failed to 'spare' muscular glycogen [32]. The reason for this seems to be that competition between substrates for respiration by working muscle is highly selective, rigidly favouring carbohydrate as relative workloads increase, despite alternative substrate provision [33,34] (see later section on fuel selection in exercise). However, as muscle carbohydrate content falls during exhaustive exercise, muscle oxidation of fatty acids does increases with a fall in respiratory quotient (RQ) [35]. A concomitant increase in blood ketone concentration is also observed, with circulating $\beta \mathrm{HB}$ levels of $1-2 \mathrm{mM}$ seen following exhaustive exercise [36,37], in contrast to post-absorptive ketosis of $\sim 0.1 \mathrm{mM}$ [37]. It seems that our evolutionary response to energy crisis is hardwired to favour ketosis, and endurance exercise performance may be constrained by the same metabolic considerations pertinent to the starvation condition.

\section{Dietary substrates alter mitochondrial fuel preference} Randle and colleagues described the glucose-free fatty acid (FFA) cycle in 1963, suggesting an overall substrate hierarchy dominated by fatty acid selection in preference to carbohydrate for oxidative phosphorylation [38]. The capacity of the mitochondria to alter its preferential fuel selection was initially recognised by the apparent decrease in glycolysis in the presence of increased FFA. Randle suggested that carbohydrate oxidation could be regulated by the fatty acid-induced suppression of the pyruvate dehydrogenase complex (PDC) activation by a high acetyl-CoA/CoA or nicotinamide adenine dinucleotide $(\mathrm{NADH}) / \mathrm{NAD}^{+}$ratio. This in turn elevates citrate concentrations, inhibiting glycolytic flux at the level of phosphofructokinase. Whilst generally speaking, the Randle cycle approximates substrate hierarchy accurately at rest, the same is not necessarily true when cellular conditions change, such as during exercise.

\section{Dietary substrates and muscle fuel selection during exercise}

The cellular mechanisms that control mitochondrial preference for substrates during exercise are still to be fully understood. Recent work has proven that the classical 'glucose-FFA' cycle is inadequate as a model of fuel selection during heavy exercise $[33,39]$, as working muscle becomes increasingly reliant on glycolysis to provide acetyl-CoA to the tricarboxylic acid cycle (TCA) cycle, independent of FFA availability [34]. The rigid preference by muscle for carbohydrate during exercise reinforces the importance of muscular and hepatic glycogen stores for powering sustained exercise [30,40,41]. Current nutritional practice in exercise performance advocates the exogenous supplementation of carbohydrates to maintain glycaemia [42], 
with growing evidence to support a performanceenhancing effect during an exercise longer than $1 \mathrm{~h}$ $[43,44]$ (for reviews, see [45-47]). Numerous studies have investigated dietary and pharmacological strategies to increase the exogenous provision of carbon units to the TCA cycle during exercise. Conflicting reports over the benefits of raising circulating fatty acids to spare glucose metabolism [48-52] and the failure of many studies to show convincing benefits of carbohydrate feeding [53-58] make a unifying hypothesis regarding optimal dietary strategy for performance difficult [59].

However, the nutritional provision of ketone bodies as an alternative fuel substrate may well provide a powerful signal to reinstate 'Randle cycle' competition between substrates for oxidative respiration $[60,61]$. Current literature on dietary fuel selection mechanisms has not considered the role of ketone bodies as a major fuel source in great depth, although the latter are well known to be metabolised by skeletal muscle [21]. Ketone bodies have a similar RQ to that of glucose (AcAc $=1.0, \beta \mathrm{HB}=0.89$ ) if completely oxidised [62] and do not rely on glucose transporter (GLUT) or fatty acid transporters to enter cytosolic or mitochondrial spaces [63], unlike carbohydrates or fat.

Previous evidence on the role of ketone bodies to fuel muscular work in humans have been confounded by the inability to elevate ketone concentrations without the effects of starvation $[64,65]$ or elevated fatty acids [66]. This lack of facility to induce acute ketosis has meant that all of the published literature methods to study fuel selection during ketosis have employed infusions of either AcAc or $\beta \mathrm{HB}$ in order to study the role of ketone bodies as oxidative substrates, or signals, in human subjects [67]. Narrowing this search further to those studies conducted during whole body exercise in healthy subjects results in only a handful of published reports, derived from fewer than 30 people $[68,69]$. None of this work studied strenuous exercise, concomitant muscle metabolism or performed work in athletic cohorts. These early investigations sought to determine the regulation of ketogenesis and its role in starvation, obesity and diabetes [70]. However, their findings leave many questions unanswered. Firstly, one of the most significant findings by Fery and Balasse et al. was a profound stimulation of exercise on the metabolic clearance of ketone bodies in overnight fasted subjects [69,71]. In two further studies, subjects performed relatively lowintensity exercise $\left(40 \%-50 \% \mathrm{VO}_{2 \mathrm{Max}}\right)$ for $30 \mathrm{~min}$ and $2 \mathrm{~h}$, respectively, during constant infusions of either acetoacetate or $\beta \mathrm{HB}[69,72]$. Circulating ketone bodies fell by $>1 \mathrm{mM}$, rates of disappearance of ketones markedly increased and metabolic clearance of ketone increased approximately five- to eightfold above resting conditions. Furthermore, the percent of $\mathrm{CO}_{2}$ derived from the oxidation of ketones was consistently between $10.1 \%$ and $17.6 \%$ of total $\mathrm{CO}_{2}$, suggesting significant oxidation of ketones in overnight fasted subjects, even at relatively low workloads. This may have an important contribution to energy expenditure, thereby conserving whole body glucose stores during exercise, in addition to altering mitochondrial fuel selection and energetics, both important determinants of physical performance.

\section{Thermodynamics of muscle metabolism as determinants of oxidative performance \\ Conservation of energy and mitochondrial fuel selection}

The energy currency ATP is required to power all mammalian cells. Cells derive most of their chemical energy from the combustion of carbon substrates using oxygen (although some specialised cells rely solely on anaerobic energy production). This highly regulated process occurs within the mitochondria, specialised organelles sensitive to the changing energy requirements of the cell. During exercise, ATP demand increases dramatically, placing great pressure on mitochondrial oxidative metabolism. Manipulating diet, and therefore substrate physiology, unquestionably alters human performance, and although poorly acknowledged, the reasons for these effects may lie in the thermodynamic relationships at the core of mitochondrial oxidation.

In simple terms, our body is driven by a series of controlled chemical reactions, resulting in the oxidation of carbon substrates to water and $\mathrm{CO}_{2}$. Thus, for a given quantity of fuel, the maximum amount of non-expansive work that can be obtained from a closed system is denoted by the Gibbs free energy (G). Described by Willard Gibbs in 1873 [73], this translation of the second law of thermodynamics relates enthalpy and entropy to the conservation of energy, expressed as:

$$
\Delta G=\Delta H-T \Delta S
$$

Therefore, substrates with greater enthalpy can yield greater potential energy to power a system if fully oxidised. Thus, heat of combustion is of inherent importance when considering the potential impact of mitochondrial substrate selection on energetic performance (Table 1). For example, pyruvate, the end product of glycolysis, has a lower heat of combustion per $C_{2}$ unit than either $\beta \mathrm{HB}$ or palmitate, providing less potential energy to the electron transport chain.

\section{Table 1 Heat of combustion of selected fuels}

\begin{tabular}{lll}
\hline Substrate & $\Delta \mathbf{H}^{\circ} \mathbf{~} \mathbf{c a l} / \mathbf{m o l}$ & $\Delta \mathbf{H}^{\circ} \mathbf{~ c a l} / \mathbf{m o l ~} \mathbf{C}_{\mathbf{2}}$ units \\
\hline $\mathrm{C}_{18} \mathrm{H}_{32} \mathrm{O}_{2}$ (Palmitate) & $-2,384.8$ & -298.0 \\
$\mathrm{C}_{4} \mathrm{H}_{8} \mathrm{O}_{3}$ ( $\beta$ Hydroxybutyrate) & -487.2 & -243.6 \\
$\mathrm{C}_{6} \mathrm{H}_{12} \mathrm{O}_{6}$ (Glucose) & -669.9 & -223.6 \\
$\mathrm{C}_{3} \mathrm{H}_{6} \mathrm{O}_{3}$ (Lactate) & -326.8 & -217.9 \\
$\mathrm{C}_{3} \mathrm{H}_{4} \mathrm{O}_{3}$ (Pyruvate) & -278.5 & -185.7 \\
\hline
\end{tabular}

Adapted from Veech et al. [96]. 
From Equation 1, we can also see that the larger the value of Gibbs free energy, the more energy can be exchanged with the surrounding system. In non-standard chemical conditions, such as those encountered in human physiology or other biological conditions [74], an alternative expression of this equation is used:

$$
\Delta G^{\prime}=\Delta G^{\circ}+R T \ln Q
$$

Therefore, by integrating the reaction quotient $(\mathrm{Q})$ into its expression, Equation 2 allows the specific chemical conditions where the reaction is taking place and the principle of mass conservation to be incorporated into the calculation of free energy. Thus, Equation 2 can be further related to cellular substrate energetics, where the common endpoint for the conservation of energy arising from substrate oxidation is in the phosphate bonds of ATP. Therefore, the latent energy conserved in these bonds ( $\left.\Delta G_{\text {ATP hydrolysis }}\right)$ can be calculated as:

$$
\Delta G^{\prime}=\Delta G^{\circ}+\ln \frac{[A D P][P i]}{[A T P]}
$$

A further consideration for the application of thermodynamics in metabolism is the concept of nearequilibrium relationships between metabolic pathways, each part of a complex interdependent network, with an overall net forward flux [75]. This kinetic linkage between redox couples of the major fuel pathways and the phosphorylation potential of the cell has its origins in the early work of Haldane [76], Klingenburg [75], Krebs [77-80] and later Veech [81-85] among many others. Therefore, despite the apparent simplicity of oxidising substrates to liberate chemical energy, the useful free energy of substrate combustion to perform work is influenced by the architecture of the metabolic pathway and the enthalpy of the fuel [86]. For these reasons, the available free energy to perform work, the free energy of ATP hydrolysis $\left(\Delta G^{\prime}{ }_{\text {ATP }}\right)$, is not equivalent for all dietary fuels.

\section{Mitochondrial redox state is affected by the substrate oxidised}

As discussed above, the generation of the universal energy currency, ATP, requires the conversion of $\mathrm{ADP}+\mathrm{Pi}$ to ATP. This process is driven by the electrochemical potential difference across the inner mitochondrial membrane. However, it should be noted that the donation of electrons to power the electron transport chain is from the reducing equivalents, $\mathrm{NADH}$ and flavin adenine dinucleotide $\left(\mathrm{FADH}_{2}\right)$, both of which can be described as a redox couple with respect to the standard membrane potential (that of the hydrogen electrode, $E_{h}$ ) [84]. These reducing equivalents undergo cyclical reduction and oxidation, intimately linking the TCA cycle and the electron transport chain. It becomes apparent that the larger the electrical potential difference between mitochondrial phases created by the pumping of protons into the inter-mitochondrial space [87], the greater the potential free energy. Therefore, consideration for the redox couples of the electron transport chain can be integrated into the calculation of free energy $\left(\Delta G^{\prime}\right)$, calculated as:

$$
\Delta G^{\prime}=-n F \Delta E
$$

(where $n$ is the number of electrons and $F$ is the Faraday constant). The electrochemical gradient $(\Delta E)$ created by the electron transport chain relies on the continuous supply of reducing equivalents from $\mathrm{NADH}$ and $\mathrm{FADH}_{2}$. The energy of the proton motive force generated by the pumping of protons from the mitochondrial matrix (via complexes 1, 3 and 4 of the electron transport chain) can vary depending on the redox span between complexes of the electron transport chain $[88,89]$. Therefore, the relative supply of reducing equivalents generated by the architecture of each pathway influences the electrical potential difference between the $\left(\mathrm{NAD}^{+} / \mathrm{NADH}\right)$ couple, the co-enzyme $\mathrm{Q}$ couple, and thus the $\Delta \mathrm{G}^{\prime}{ }_{\mathrm{ATP}}$.

\section{Ketone bodies alter mitochondrial energy transduction}

Ketone bodies are more chemically reduced than pyruvate and result in an increased electron transport chain redox span through the reduction of the $\mathrm{NAD}^{+}$couple and oxidation of the co-enzyme Q couple. This, in turn, creates a greater $\Delta G^{\prime}{ }_{\text {ATP }}$ for the generation of ATP. In the working rat heart, this has been reported to result in an increase in hydraulic efficiency (expressed as work in $\mathrm{J} / \mathrm{mol}$ of $\mathrm{O}_{2}$ consumed) of $28 \%$ during perfusion of ketone bodies compared with glucose alone [90]. Alternative substrates such as fat are highly reduced, and thus contain a large amount of potential energy, but require more $\mathrm{O} 2 / \mathrm{mol}$ of $\mathrm{C} 2$ to oxidise. In addition, the effective redox span of the mitochondrial electron transport chain is lower when fatty acids are oxidised, due to half of the reducing equivalents produced in $\beta$-oxidation being in the form of FADH2 rather than NADH. This reduces (comparatively) the redox span between $\left(\mathrm{NAD}^{+} / \mathrm{NADH}\right)$ couple and the co-enzyme $\mathrm{Q}$ couple thus reducing $\Delta G^{\prime}$ ATP. Furthermore, elevated fatty acids induce the expression of uncoupling proteins which dissipate stored mitochondrial proton gradients and contribute to worsening metabolic efficiency through non-ATP generating metabolic cost [2].

The observed improvements in metabolic efficiency (or energetic performance) in the isolated heart may translate to greater muscular work output for a given oxygen requirement during exercise and thus sustain physical endurance. The implications of ketosis to enhance 
mitochondrial energetics and their potential role in disease are discussed in the detailed reviews of Veech et al. [89,91].

\section{Applications for ketosis to enhance athletic metabolism}

Providing ketone bodies to spare intramuscular reserves mimics the physiology of starvation, where ketone bodies provide fuel for oxidation and act as signals limiting glucose and glycogen metabolism [90]. The supplementation of ketone bodies in physiologic states other than starvation may make use of our body's hardwired metabolic response to elevated blood ketones. Ketones can be readily oxidised by the working muscle and exert a strong influence over glycolytic flux in vivo [21]. Elevated concentrations of ketones in a perfused working rat heart resulted in the suppression of glycolytic flux, even reporting a promotion of glycogen synthesis during continuous hydraulic work $[90,92]$.

Ketone bodies could provide a logical alternative for the delivery of carbon units to the TCA cycle, free of the limitations in mitochondrial and sarcolemmal membrane transport that restrict fat and carbohydrate utilisation [63]. Further to acting as an alternative carbon supply, the greater enthalpy of ketone combustion over pyruvate could provide greater potential energy for conservation in the phospho-anhydridic bonds of ATP. Therefore, mimicking the physiology of starvation during exercise (by raising circulating ketone concentrations) may alter the hierarchical preference of mitochondrial substrate selection, effecting an improvement in substrate energetics.

\section{New frontiers in ketone metabolism}

Previously, a controlled physiological ketosis required adherence to a low-carbohydrate high-fat 'ketogenic diet', starvation or the administration/infusion of the salts of acetoacetate or D- $\beta$-hydroxybutyrate $[93,94]$. All of these methods are unpleasant, impractical or have potentially harmful side effects [95]. One possible solution to this problem is to create an ester linkage between a ketone body and an alcohol, such as 1,3-butanediol, that itself undergoes metabolism to a ketone via hepatic conversion [96]. This ester bond can be easily broken by gut or tissue esterases to release both components without the need for a salt or acid [97]. Such esters have recently been developed and tested in humans [98] and are capable of inducing the biochemical appearance of prolonged fasting within minutes of consumption. These new dietary methods to deliver a pure ketosis from exogenous sources allows, for the first time, an evaluation of ketone body metabolism itself, free of the confounding milieu required to produce ketone bodies endogenously [97] (Figure 1).

\section{Ketone esters and nutritional ketosis}

The first practical ketone ester synthesised to be hydrolysed in plasma, free of a sodium salt load and effectively induce a rapid circulating ketonaemia was described by Birkhahn et al. $[99,100]$ in the late 1970s. This monoester of glycerol and acetoacetate (monoacetoacetin) was delivered parenterally to rats. Prior to this, the butyl alcohol, $R S$-1, 3-butanediol, was known to be oxidised in the liver, producing both $\beta \mathrm{HB}$ and AcAc in isolated liver mitochondria [101], rats [102] and humans [103]. Two iso-enantiomers of $\beta \mathrm{HB}$ were produced from the administration of a racemic mix of RS-1,3-butanediol, with the $S$ enantiomer not naturally found within the body [101], although it is oxidised by body tissues [104-106]. In 1995, the administration of both oral and parenteral ketone esters containing RS-1,3-butanediol, and either $\beta \mathrm{HB}$ or acetoacetate, was described in pigs by Desrochers [107]. Now, human safety and tolerability trials have been successfully undertaken using ketone monoesters of $\beta \mathrm{HB}$ and R-1,3-butanediol [98]; the opportunity to examine ketosis in detail during a number of therapeutic and physiological conditions appears a step closer.

\section{Not all ketosis is equivalent; high-fat diets vs. exogenous ketones}

The popularity of ketosis as a weight loss intervention by adherence to a high-fat, low-carbohydrate diet (for systematic review, see [108]) owes much of its notoriety to the Atkin's diet fad of the early 2000s [109]. However, ketogenic diets are far from a novel discovery. The Inuits had almost exclusive intake of dietary fat and protein throughout the long arctic winter, where naturally occurring dietary carbohydrate sources are virtually nonexistent. However, the metabolic conditions of chronic dietary ketosis are in stark contrast to the rapid exogenous delivery of ketone bodies now possible with ketone esters. In essence, the efficacy of the low-carbohydrate diet is dependent upon depleted hepatic and muscle carbohydrate reserves increasing circulating FFA and endogenous ketone body production. Low muscular carbohydrate content during heavy sustained exercise is well known to impair physical performance [30]. The recent interest in low-carbohydrate diets to enhance submaximal exercise tolerance [110-112] are not thought to be driven by ketosis, rather by an up-regulation in fatty acid oxidation [51] (in lieu of low muscle glycogen content) over weeks of specific dietary intervention [113]. Acute exogenous delivery of ketone bodies elevates ketone levels without the prior depletion of muscle carbohydrates necessary to induce ketosis via endogenous production.

\section{Conclusion}

Ketone bodies have long been overlooked as alternative substrates to power our bodies. The reasons for this are numerous but in no small part related to the negative connotations associated with the discovery of ketosis in critically ill diabetic patients $[22,114]$. Furthermore, ketosis has 


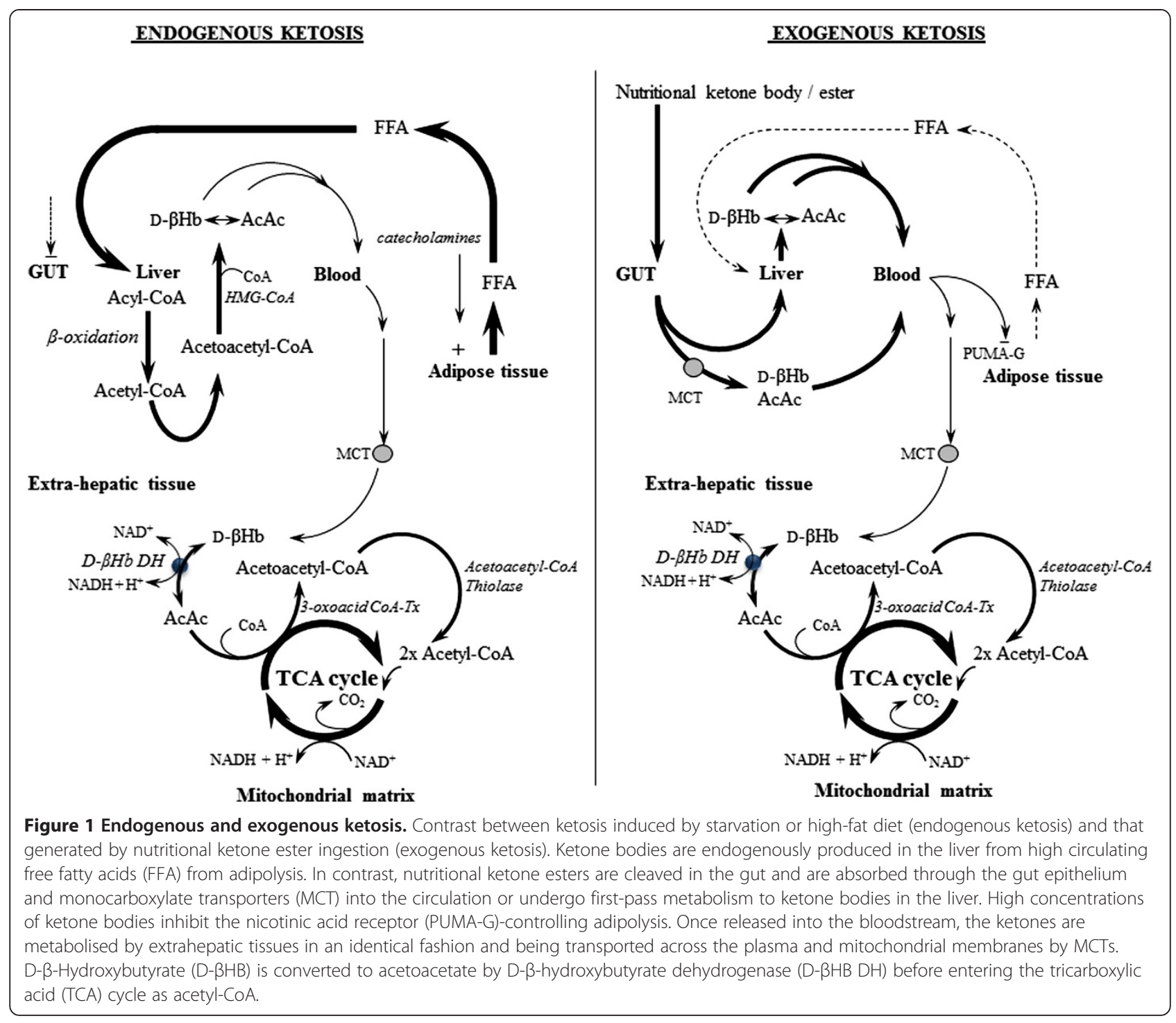

until now only been achievable in starvation states or high-fat low-carbohydrate diets, conditions which are unpleasant, difficult to sustain and negate many of the desirable effects of ketone metabolism [115]. The evolutionary conservation of ketone bodies as energy substrates has a sound rationale, their being thermodynamic advantages to their oxidation, as well as the preservation of alternative energy reserves essential to our survival. The importance of oxidative efficiency and conservation of carbohydrate reserves is vital not just in starvation but on a greatly accelerated scale during endurance exercise. Exercise places large demands on oxidative metabolism for the sustained provision of ATP to the working muscle. Finite reserves of intramuscular glycogen, and a loss of flexibility for mitochondrial fuel selection during high intensities of aerobic work [33], underline the importance of substrate metabolism for athletic performance. Given the well-characterised demands of endurance exercise and the importance of dietary substrates on athletic metabolism, there is a clear rationale for the nutritional provision of exogenous ketone bodies in this context. With the recent development of novel forms of dietary ketone ester now undergoing rodent and human testing, the stigma of this much maligned substrate may yet be challenged.

\section{Abbreviations}

$\beta$ HB: D- $\beta$-hydroxybutyrate; AcAc: acetoacetate; FFA: free fatty acids; TCA: tricarboxylic acid cycle; ATP: adenosine triphosphate; NADH: nicotinamide adenine dinucleotide; $\mathrm{FADH}_{2}$ : flavin adenine dinucleotide; $\mathrm{P}_{\mathrm{i}}$ : inorganic phosphate; ADP: adenine diphosphate; RQ: respiratory quotient.

\section{Competing interests}

Professor Kieran Clarke is a non-executive director of TdeltaS Ltd, a spin out company of the University of Oxford, which owns the intellectual property rights to the D-3- $\beta$-hydroxybutyrate-1,3-butanediol ketone monoester.

Dr Peter Cox declares that he has no competing interests.

\section{Authors' contributions}

PC conceived the review, and both PC and KC drafted the manuscript. Both authors read and approved the final manuscript. 
Received: 5 June 2014 Accepted: 29 September 2014

Published: 29 Oct 2014

\section{References}

1. Krebs HA, Johnson WA: Metabolism of ketonic acids in animal tissues. Biochem J 1937, 31(4):645-60.

2. Rolfe DFS, Brown GC: Cellular energy utilization and molecular origin of standard metabolic rate in mammals. Physiol Rev 1997, 77(3):731-758.

3. Palange P, Ward SA, Carlsen KH, Casaburi R, Gallagher CG, Gosselink R, O'Donnel DE, Puente-Maestu L, Schols AM, Singh S, Whipp BJ: Recommendations on the use of exercise testing in clinical practice. Eur Respir J 2007, 29(1):185-209.

4. Ats: ATS/ACCP statement on cardiopulmonary exercise testing. Am J Respir Crit Care Med 2003, 167(2):211-277.

5. Spina RJ, Chi M, Hopkins MG, Nemeth P, Lowry O, Holloszy J: Mitochondrial enzymes increase in muscle in response to 7-10 days of cycle exercise. J Appl Physiol 1996, 80(6):2250-2254.

6. Holloszy JO: Biochemical adaptations in muscle effects of exercise on mitochondrial oxygen uptake and respiratory enzyme activity in skeletal muscle. J Biol Chem 1967, 242(9):2278-2282.

7. Deuster P, Chrousos G, Luger A, DeBolt J, Bernier L, Trostmann U, Kyle S, Montgomery L, Loriaux D: Hormonal and metabolic responses of untrained, moderately trained, and highly trained men to three exercise intensities. Metabolism 1989, 38(2):141-148.

8. Barnard RJ, Edgerton VR, Peter J: Effect of exercise on skeletal muscle. I. Biochemical and histochemical properties. J Appl Physiol 1970, 28(6):762-766.

9. Tarnopolsky MA, Rennie CD, Robertshaw HA, Fedak-Tarnopolsky SN, Devries $M C$, Hamadeh MJ: Influence of endurance exercise training and sex on intramyocellular lipid and mitochondrial ultrastructure, substrate use, and mitochondrial enzyme activity. Am J Physiol Regul Integr Comp Physiol 2007, 292(3):R1271-R1278.

10. Martin WH, Dalsky GP, Hurley BF, Matthews DE, Bier DM, Hagberg JM, Rogers MA, King DS, Holloszy JO: Effect of endurance training on plasmafree fatty-acid turnover and oxidation during exercise. Am J Physiol 1993 265(5):E708-E714.

11. Coggan AR, Kohrt WM, Spina RJ, Bier D, Holloszy J: Endurance training decreases plasma glucose turnover and oxidation during moderateintensity exercise in men. J Appl Physiol 1990, 68(3):990-996.

12. Kiens B, Essen-Gustavsson B, Christensen NJ, Saltin B: Skeletal muscle substrate utilization during submaximal exercise in man: effect of endurance training. J Physiol 1993, 469(1):459-478

13. Holloszy JO, Coyle EF: Adaptations of skeletal muscle to endurance exercise and their metabolic consequences. J Appl Physiol 1984, 56(4):831-838.

14. Cox JH, Cortright RN, Dohm GL, Houmard JA: Effect of aging on response to exercise training in humans: skeletal muscle GLUT-4 and insulin sensitivity. J App/ Physiol 1999, 86(6):2019-2025.

15. Zierath JR: Invited review: exercise training-induced changes in insulin signaling in skeletal muscle. J App/ Physiol 2002, 93(2):773-781.

16. Etgen $G \mathrm{Jr}$, Brozinick J Jr, Kang H, Ivy J: Effects of exercise training on skeletal muscle glucose uptake and transport. Am J Physiol Cell Physiol 1993, 264(3):C727-C733.

17. Hawley JA: Adaptations of skeletal muscle to prolonged, intense endurance training. Clin Exp Pharmacol Physiol 2002, 29(3):218-222.

18. Winder WW, Baldwin KM, Holloszy JO: Enzymes involved in ketone utilization in different types of muscle: adaptation to exercise. Eur J Biochem 1974, 47(3):461-467.

19. Johnson R, Walton J, Krebs H, Williamson D: Metabolic fuels during and after severe exercise in athletes and non-athletes. Lancet 1969, 294(7618):452-455.

20. Bloom S, Johnson R, Park D, Rennie M, Sulaiman W: Differences in the metabolic and hormonal response to exercise between racing cyclists and untrained individuals. J Physiol 1976, 258(1):1-18.

21. Robinson AM, Williamson DH: Physiological roles of ketone bodies as substrates and signals in mammalian tissues. Physiol Rev 1980, 60(1):143-87.

22. Laffel L: Ketone bodies: a review of physiology, pathophysiology and application of monitoring to diabetes. Diabetes Metab Res Rev 1999, 15(6):412-426.

23. Cahill GF Jr: Fuel metabolism in starvation. Annu Rev Nutr 2006, 26:1-22.

24. Fukao T, Lopaschuk GD, Mitchell GA: Pathways and control of ketone body metabolism: on the fringe of lipid biochemistry. Prostag Leukotr Essent Fatty Acids 2004, 70(3):243-251.
25. McCue MD: Starvation physiology: reviewing the different strategies animals use to survive a common challenge. Comp Biochem Physiol A Mol Integr Physiol 2010, 156(1):1-18

26. Cahill G Jr, Felig P, Owen O, Wahren J: Metabolic adaptation to prolonged starvation in man. Nordisk Med 1970, 83(3):89.

27. Cahill GF Jr, Owen OE: Starvation and survival. Trans Am Clin Climatol Assoc 1968, 79:13.

28. Owen OE, Morgan AP, Kemp HG, Sullivan JM, Herrera MG, Cahill GF: Brain metabolism during fasting. J Clin Invest 1967, 46(10):1589.

29. Felig P, Owen OE, Wahren J, Cahill GF: Amino acid metabolism during prolonged starvation. J Clin Invest 1969, 48(3):584.

30. Bergstrom J, Hermansen L, Hultman E, Saltin B: Diet, muscle glycogen and physical performance. Acta Physiologica Scandinavia 1967, 71(2):140-50.

31. Bergstrom J, Hultman E: Nutrition for maximal sports performance. J Am Med Assoc 1972, 221(9):999-1006.

32. Bosch AN, Dennis SC, Noakes TD: Influence of carbohydrate ingestion on fuel substrate turnover and oxidation during prolonged exercise. J Appl Physiol 1994, 76(6):2364-2372.

33. van Loon LJ, Greenhaff PL, Constantin-Teodosiu D, Saris WH, Wagenmakers $\mathrm{AJ}$ : The effects of increasing exercise intensity on muscle fuel utilisation in humans. J Physio/ 2001, 536(Pt 1):295-304

34. Romijn J, Coyle E, Sidossis L, Zhang X, Wolfe R: Relationship between fatty acid delivery and fatty acid oxidation during strenuous exercise. J Appl Physiol 1995, 79(6):1939-1945

35. Brooks GA, Mercier J: Balance of carbohydrate and lipid utilization during exercise: the "crossover" concept. J Appl Physiol 1994, 76(6):2253-2261.

36. Koeslag J: Post-exercise ketosis and the hormone response to exercise: a review. Med Sci Sports Exerc 1982, 14(5):327-334

37. Johnson $\mathrm{RH}$, Walton $\mathrm{L}$, Krebs HA, Williams DH: Metabolic fuels during and after severe exercise in athletes and non-athletes. Lancet 1969, 2(7618):452.

38. Randle PJ, Garland PB, Newsholme EA, Hales CN: Glucose fatty-acid cycle. Its role in insulin sensitivity and metabolic disturbances of diabetes mellitus. Lancet 1963, 1(728):785.

39. Romijn J, Coyle E, Sidossis L, Gastaldelli A, Horowitz J, Endert E, Wolfe R: Regulation of endogenous fat and carbohydrate metabolism in relation to exercise intensity and duration. Am J Physiol Endocrinol Metab 1993, 265(3):E380-E391.

40. Hermansen L, Hultman E, Saltin B: Muscle glycogen during prolonged severe exercise. Acta Physiologica Scandinavica 1967, 71(2-3):129-139.

41. Coyle EF: Substrate utilization during exercise in active people. Am J Clin Nutr 1995, 61(4):S968-S979.

42. ACSM DOC: A Joint Position Statement: nutrition and athletic performance American College of Sports Medicine, American Dietetic Association, and Dietitians of Canada. Med Sci Sports Exerc 2000, 32(12):2130-2145.

43. Coyle E, Hagberg J, Hurley B, Martin W, Ehsani A, Holloszy J: Carbohydrate feeding during prolonged strenuous exercise can delay fatigue. $J$ Appl Physiol 1983, 55(1):230-235.

44. Currell $K$, Jeukendrup AE: Superior endurance performance with ingestion of multiple transportable carbohydrates. Med Sci Sports Exerc 2008, 40(2):275

45. Jeukendrup AE: Carbohydrate feeding during exercise. Eur J Sport SCi 2008, 8(2):77-86.

46. Jeukendrup AE: Carbohydrate intake during exercise and performance. Nutrition 2004, 20(7):669-677.

47. Burke LM, Hawley JA: Carbohydrate and exercise. Curr Opin Clin Nutr Metab Care 1999, 2(6):515.

48. Hargreaves M, Hawley JA, Jeukendrup A: Pre-exercise carbohydrate and fat ingestion: effects on metabolism and performance. J Sports Sci 2004, 22(1):31-38.

49. Jeukendrup A, Saris W, Wagenmakers A: Fat metabolism during exercise: a review. Int J Sports Med 1998, 19:371-9.

50. Hawley JA: Effect of increased fat availability on metabolism and exercise capacity. Med Sci Sports Exerc 2002, 34(9):1485-1491.

51. Cameron-Smith D, Burke LM, Angus DJ, Tunstall RJ, Cox GR, Bonen A, Hawley JA, Hargreaves M: A short-term, high-fat diet up-regulates lipid metabolism and gene expression in human skeletal muscle. Am J Clin Nutr 2003, 77(2):313-318.

52. Vukovich MD, Costill DL, Hickey MS, Trappe SW, Cole KJ, Fink WJ: Effect of fat emulsion infusion and fat feeding on muscle glycogen utilization during cycle exercise. J Appl Physiol 1993, 75(4):1513-1518.

53. Bonen A, Malcolm SA, Kilgour RD, Macintyre KP, Belcastro AN: GlucoseIngestion before and during intense exercise. J Appl Physiol 1981, 50(4):766-771 
54. Flynn MG, Costill DL, Hawley JA, Fink WJ, Neufer PD, Fielding RA, Sleeper MD: Influence of selected carbohydrate drinks on cycling performance and glycogen use. Med Sci Sports Exerc 1987, 19(1):37-40.

55. Madsen K, MacLean DA, Kiens B, Christensen D: Effects of glucose, glucose plus branched-chain amino acids, or placebo on bike performance over 100 km. J Appl Physiol 1996, 81(6):2644-2650.

56. Murray R, Paul GL, Seifert JG, Eddy DE, Halaby GA: The effects of glucose, fructose, and sucrose ingestion during exercise. Med Sci Sports Exerc 1989, 21(3):275-282

57. Mitchell JB, Costill DL, Houmard JA, Fink WJ, Pascoe DD, Pearson DR: Influence of carbohydrate dosage on exercise performance and glycogen metabolism. J Appl Physiol 1989, 67(5):1843-9.

58. Jentjens R, Cale C, Gutch C, Jeukendrup A: Effects of pre-exercise ingestion of differing amounts of carbohydrate on subsequent metabolism and cycling performance. Eur J Appl Physiol 2003, 88(4):444-452.

59. Heneghan C, Perera R, Nunan D, Mahtani K, Gill P: Forty years of sports performance research and little insight gained. Br Med J 2012, 345:e4797.

60. Maizels EZ, Ruderman NB, Goodman MN, Lau D: Effect of acetoacetate on glucose-metabolism in soleus and extensor digitorum longus muscles of rat. Biochem J 1977, 162(3):557-568.

61. Ruderman NB, Saha AK, Vavvas D, Witters LA: Malonyl-CoA, fuel sensing, and insulin resistance. Am J Physiol Endocrinol Metab 1999, 276(1):E1-E18

62. Frayn $\mathrm{KN}$ : Calculation of substrate oxidation rates in vivo from gaseous exchange. J Appl Physiol 1983, 55(2):628-634.

63. Halestrap AP, Meredith D: The SLC16 gene family-from monocarboxylate transporters (MCTs) to aromatic amino acid transporters and beyond. Eur J Physiol 2004, 447(5):619-628.

64. Hagenfeldt L, Wahren J: Human forearm muscle metabolism during exercise. 6. Substrate utilization in prolonged fasting. Scand J Clin Lab Invest 1971, 27(4):299.

65. Hagenfeldt L, Wahren J: Human forearm muscle metabolism during exercise. 3. Uptake release and oxidation of beta-hydroxybutyrate and observations on beta-hydroxybutyrate/acetoacetate ratio. Scand I Clin Lab Invest 1968, 21(4):314.

66. Ahlborg G, Felig P, Hagenfeldt L, Hendler R, Wahren J: Substrate turnover during prolonged exercise in man. Splanchnic and leg metabolism of glucose, free fatty acids, and amino acids. J Clin Invest 1974, 53(4):1080-1090.

67. Beylot M, Beaufrere B, Normand S, Riou JP, Cohen R, Mornex R: Determination of human ketone-body kinetics using stable-isotope labeled tracers. Diabetologia 1986, 29(2):90-96.

68. Fery F, Balasse EO: Response of ketone-body metabolism to exercise during transition from postabsorptive to fasted state. Am J Physiol 1986, 250(5):E495-E501.

69. Fery F, Balasse EO: Ketone body turnover during and after exercise in overnight-fasted and starved humans. Am J Physiol 1983, 245(4):E318-E325.

70. Fery F, Balasse EO: Ketone body production and disposal in diabetic ketosis - a comparison with fasting ketosis. Diabetes 1985, 34(4):326-332

71. Balasse EO, Fery F, Neef MA: Changes induced by exercise in rates of turnover and oxidation of ketone bodies in fasting man. $J$ Appl Physiol 1978, 44(1):5-11

72. Fery F, Balasse EO: Effect of exercise on the disposal of infused ketone bodies in humans. J Clin Endocrinol Metab 1988, 67(2):245-250.

73. Gibbs JW: A method of geometrical representation of the thermodynamic properties of substances by means of surfaces. 1873, 2:382-404. Reprinted in Sci Pap1, pp 33-54.

74. Alberty RA: Standard Gibbs free energy, enthalpy, and entropy changes as a function of $\mathrm{pH}$ and $\mathrm{pMg}$ for several reactions involving adenosine phosphates. J Biol Chem 1969, 244(12):3290.

75. Veech RL: The determination of the redox states and phosphorylation potential in living tissues and their relationship to metabolic control of disease phenotypes. Biochem Mol Biol Educ 2006, 34(3):168-179.

76. Briggs $G E$, Haldane JBS: A note on the kinetics of enzyme action Biochem J 1925, 19(2):338.

77. Stubbs $M$, Veech $\mathrm{R}$, Krebs $\mathrm{H}$ : Control of the redox state of the nicotinamide-adenine dinucleotide couple in rat liver cytoplasm. Biochem J 1972, 126(1):59.

78. Krebs H, Veech R: Equilibrium relations between pyridine nucleotides and adenine nucleotides and their roles in the regulation of metabolic processes. Adv Enzyme Regul 1969, 7:397-413.
79. Veech R, Raijman L, Krebs H: Equilibrium relations between the cytoplasmic adenine nucleotide system and nicotinamide-adenine nucleotide system in rat liver. Biochem J 1970, 117(3):499.

80. Veech RL, Eggleston LV, Krebs HA: The redox state of free nicotinamideadenine dinucleotide phosphate in the cytoplasm of rat liver. Biochem $J$ 1969, 115(4):609-19.

81. Veech RL, Eggleston LV, Krebs HA: The energetics of ion distribution: the origin of the resting electric potential of cells. IUBMB Life 2002, 54(5):241-52

82. Kashiwaya Y, King MT, Veech RL: Substrate signaling by insulin: a ketone bodies ratio mimics insulin action in heart. Am J Cardiol 1997, 80(3A):50A-64A.

83. Wilson DF, Stubbs M, Veech RL, Erecińska M, Krebs HA: Equilibrium relations between the oxidation-reduction reactions and the adenosine triphosphate synthesis in suspensions of isolated liver cells. Biochem 1974, 140(1):57.

84. Veech RL, Lawson J, Cornell N, Krebs HA: Cytosolic phosphorylation potential. J Biol Chem 1979, 254(14):6538.

85. Veech RL, Fell DA: Distribution control of metabolic flux. Cell Biochem Funct 1996, 14(4):229-36

86. Rider O, Cox P, Tyler D, Clarke K, Neubauer S: Myocardial substrate metabolism in obesity. Int J Obes 2013, 37(7):972-979.

87. Mitchell PD: Chemiosmotic coupling and energy transduction J Bioenerget 1968, 3:5-24

88. Hue L, Taegtmeyer $\mathrm{H}$ : The Randle cycle revisited: a new head for an old hat. Am J Physiol Endocrinol Metab 2009, 297(3):E578-E591.

89. Veech RL, Chance B, Kashiwaya Y, Lardy HA, Cahill GR: Ketone bodies, potential therapeutic uses. IUBMB Life 2001, 51(4):241-247.

90. Sato K, Kashiwaya Y, Keon C, Tsuchiya N, King M, Radda G, Chance B, Clarke $K$, Veech R: Insulin, ketone bodies, and mitochondrial energy transduction. FASEB J 1995, 9(8):651-658.

91. Veech RL: Ketone ester effects on metabolism and transcription. J Lipid Res 2014, doi: 10.1194/jlr.R046292.

92. Kashiwaya Y, King MT, Veech RL: Substrate signaling by insulin: a ketone bodies ratio mimics insulin action in heart. Am J Cardiol 1997, 80(3A):A50-A64

93. Plecko B, Stoeckler-Ipsiroglu S, Schober E, Harrer G, Mlynarik V, Gruber S, Moser E, Moeslinger D, Silgoner H, Ipsiroglu O: Oral beta-hydroxybutyrate supplementation in two patients with hyperinsulinemic hypoglycemia: monitoring of beta-hydroxybutyrate levels in blood and cerebrospinal fluid, and in the brain by in vivo magnetic resonance spectroscopy. Pediatr Res 2002, 52(2):301-6.

94. Keller U, Lustenberger M, Stauffacher W: Effect of insulin on ketone-body clearance studied by a ketone body "clamp" technique in normal man. Diabetologia 1988, 31(1):24-29.

95. Kwiterovich PO Jr, Vining EP, Pyzik P, Skolasky R Jr, Freeman JM: Effect of a high-fat ketogenic diet on plasma levels of lipids, lipoproteins, and apolipoproteins in children. J Am Med Assoc 2003, 290(7):912-20.

96. Veech RL: The therapeutic implications of ketone bodies: the effects of ketone bodies in pathological conditions: ketosis, ketogenic diet, redox states, insulin resistance, and mitochondrial metabolism. Prostag Leukot Essent Fatty Acids 2004, 70(3):309-319.

97. Hashim SA, Vanltallie TB: Ketone body therapy: from ketogenic diet to oral administration of ketone ester. J Lipid Res 2014, doi: 10.1194/j|r.R046599.

98. Clarke K, Tchabanenko K, Pawlosky R, Carter E, Todd King M, Musa-Veloso K, Ho M, Roberts A, Robertson J, Vanitallie TB, Veech RL: Kinetics, safety and tolerability of (R)-3-hydroxybutyl (R)-3-hydroxybutyrate in healthy adult subjects. Regul Toxicol Pharmacol 2012, 63(3):401-8.

99. Birkhahn $\mathrm{RH}$, Border JR: Intravenous feeding of rat with short chain fatty acid esters. II. Monoacetoacetin. Am J Clin Nutr 1978, 31(3):436-441.

100. Birkhahn RH, Mcmenamy RH, Border JR: Monoglyceryl acetoacetate: ketone body carbohydrate substrate for parenteral-feeding of the rat J Nutr 1979, 109(7):1168-1174.

101. Desrochers S, David F, Garneau M, Jette M, Brunengraber H: Metabolism of R- or S-1,3-butanediol in perfused livers from meal-fed and starved rats. Biochem J 1992, 285:647-653

102. Tobin RB, Garthoff LH, Mehlman MA, Veech RL: Metabolite levels, redox states, and gluconeogenic enzyme-activities in livers of rats fed diets containing 1,3-butanediol. J Environ Pathol Toxicol 1978, 2(2):389-398.

103. Kies C, Tobin RB, Fox HM, Mehlman MA: Utilization of 1,3-butanediol and nonspecific nitrogen in human adults. J Nutr 1973, 103(8):1155-1163.

104. Scofield RF, Brady PS, Schumann WC, Kumaran K, Ohgaku S, Margolis JM, Landau BR: On the lack of formation of L-(+)-3-hydroxybutyrate by liver. Arch Biochem Biophys 1982, 214(1):268-272. 
105. Webber RJ, Edmond J: Utilization of L(+)-3-hydroxybutyrate, D(-)-3hydroxybutyrate, acetoacetate, and glucose for respiration and lipid-synthesis in 18-day-old rat. J Biol Chem 1977, 252(15):5222-5226.

106. Lincoln BC, Desrosiers C, Brunengraber H: Metabolism of S-3hydroxybutyrate in the perfused-rat-liver. Arch Biochem Biophys 1987, 259(1):149-156.

107. Desrochers S, Quinze K, Dugas H, Dubreuil P, Bomont C, David F, Agarwal KC, Kumar A, Soloviev MV, Powers L, Landau BR, Brunengraber H: R, S-1,3butanediol acetoacetate esters, potential alternates to lipid emulsions for total parenteral nutrition. J Nutr Biochem 1995, 6(2):111-118.

108. Bravata DM, Sanders L, Huang J, Krumholz HM, Olkin I, Gardner CD, Bravata DM: Efficacy and safety of low-carbohydrate diets: a systematic review. J Am Med Assoc 2003, 289(14):1837-1850.

109. Atkins RC: Dr. Atkins' New Diet Revolution. London: Ebury Press; 2002.

110. Phinney SD, Horton ES, Sims EAH, Hanson JS, Danforth E Jr, Lagrange BM: Capacity for moderate exercise in obese subjects after adaptation to a hypocaloric, ketogenic diet. J Clin Invest 1980, 66(5):1152.

111. Phinney SD: Ketogenic diets and physical performance. Nutr Metab (Lond) 2004, 1(1):2.

112. Lambert EV, Speechly DP, Dennis SC, Noakes TD: Enhanced endurance in trained cyclists during moderate intensity exercise following 2 weeks adaptation to a high-fat diet. Eur J Appl Physiol 1994, 69(4):287-293.

113. Phinney SD, Bistrian BR, Wolfe RR, Blackburn GL: The human metabolic response to chronic ketosis without caloric restriction: physical and biochemical adaptation. Metabolism 1983, 32(8):757-68.

114. Nosadini R, Avogaro A, Doria A, Fioretto P, Trevisan R, Morocutti A: Ketone body metabolism: a physiological and clinical overview. Diabetes Metab Rev 1989, 5(3):299-319.

115. Edwards LM, Murray AJ, Holloway CJ, Carter EE, Kemp GJ, Codreanu I, Brooker $\mathrm{H}$, Tyler DJ, Robbins PA, Clarke K: Short-term consumption of a high-fat diet impairs whole-body efficiency and cognitive function in sedentary men. FASEB J 2011, 25(3):1088-1096.

\subsection{6/2046-7648-3-17}

Cite this article as: Cox and Clarke: Acute nutritional ketosis: implications for exercise performance and metabolism. Extreme Physiology \& Medicine 2014, 3:17

\section{Submit your next manuscript to BioMed Central and take full advantage of:}

- Convenient online submission

- Thorough peer review

- No space constraints or color figure charges

- Immediate publication on acceptance

- Inclusion in PubMed, CAS, Scopus and Google Scholar

- Research which is freely available for redistribution 